Yoshitoshi, E.R. '; Yoshitoshi², F.N.; Santos, R.C'; Smetana,G.C.M. '; Taboada, P. ${ }^{3}$; Santos, F.A .M. ${ }^{4}$

\section{7 - Obstrução gástrica por pólipos múltiplos em Akita. Relato de caso}

\author{
1- Clínica Veterinária Pront-Cão, São Paulo-SP \\ 2- Serviço de Endoscopia Veterinária da Universidade de Santo Amaro (UNISA), São Paulo-SP \\ 3- Serviço de Anatomia Patológica da Universidade de Santo Amaro (UNISA), São Paulo-SP
}

4- Universidade de Santo Amaro (UNISA), São Paulo-SP

A hipertrofia pilórica antral (ou pólipo antral) é rara e é caraterizada pela hipertrofia da mucosa e/ou da musculatura da região pilórica e antral do estômago que pode causar obstrução na saída gástrica. Essa afecção pode ser causada por irritação crônica através de processos mecânicos, químicos e inflamatórios da mucosa gástrica. Fatores ambientais associados ao estresse tem sido observados experimentalmente como causa de hiperplasia gástrica $\mathrm{em}$ mucosa de ratos. Essa afecção tem maior ocorrência em cães de porte pequeno, braquicefálico e adulto. Os sinais clínicos podem incluir vômitos intermitentes, perda de peso, anorexia, dor abdominal, melena, polidipsia entre outros. O diagnóstico é baseado na associação de sinais clínicos, diagnóstico por imagem e confirmado através de biópsia. $\mathrm{O}$ tempo de esvaziamento gástrico é normalmente requerido para identificar o nível de obstrução, tempo de retardo no esvaziamento e também observação de defeitos no preenchimento do contraste na parede gástrica. Foi atendido um cão $\mathrm{Akita}$, fêmea, 8 anos, apresentando vômitos intermitentes, diarréia e emagrecimento progressivo há um mês. Ao exame fisico foi observado desidratação e sensibilidade abdominal à palpação. Como exames complementares foram exigidos hemograma, ultrassonografia, radiografia simples e tempo de esvaziamento gástrico, observando apenas uma discreta leucocitose. À endoscopia evidenciou hiperemia, edema em parede gástrica e formações polipóides subpedunculares em antro-pilórico. Foi realizado biópsia confirmando hipertrofia pilórica antral. Foi optado pelo tratamento sintomático com ranitidina ( $2 \mathrm{mg} / \mathrm{kg} / \mathrm{TID})$, metoclopramida $(0,5 \mathrm{mg} / \mathrm{kg} / \mathrm{TID})$ e fluidoterapia com Ringer havendo melhora clínica após 20 dias.

\section{8 - Acalasia Cricofaríngea Stefanes}

S.A. '; Rodriguez, V.S.C. ${ }^{2}$; Padilha, J.G. '; Canola, J.C. '
Trata-se de uma disfagia rara, de origem desconhecida, provavelmente relacionada a um déficit neurológico congênito por comprometimento do ramo faríngeo do $10^{\circ}$ par de nervos cranianos (nervo vago), caracterizada por uma incoordenação do reflexo de deglutir. Ocorre um relaxamento inadequado do músculo cricofaríngeo nào sincronizando a sua abertura com as contrações musculares faríngeas durante a deglutição. Observa-se regurgitaçào e tosse imediatamente após a ingestão, anorexia, perda de peso grave e pneumonia por aspiração. Este distúrbio é verificado principalmente em cães jovens, as raças mais acometidas são springer spaniel inglês, cocker spaniel e cocker americano. Foi atendido no Hospital Veterinário da UNESP - Jaboticabal em 07/03/02, o caso de um cão poodle, macho, com 4 meses de idade, pesando $2 \mathrm{~kg}$, apresentando regurgitação na ingestão de liquido e sólido, perda de peso grave e pneumonia provavelmente por aspiração. $O$ diagnóstico foi confirmado através de radiografia e fluoroscopia contrastada com sulfato de bário, sendo observada a presença de contraste positivo na traquéia e nos pulmões; discreta estenose no esôfago; e abertura tardia do esfincter esofágico superior. Como tratamento cirúrgico foi realizado a miectomia do músculo cricofaringeo, obtendo-se assim o relaxamento permanente do esfincter esofágico superior. $\mathrm{O}$ animal permaneceu internado em célula de oxigênio e submetido a fluidoterapia intravenosa, nutrição parenteral, alimentação líquida e sendo medicado com amoxilina, cetoprofeno, aminofilina e D500. Apesar do tratamento intensivo para este quadro respiratório grave, o animal teve óbito no $2^{\circ}$ dia após a cirurgia. Apresentando somente o quadro de acalasia cricofaríngea o prognóstico é bom. Reservado com presença de outras disfagias intercorrentes. A cirurgia é essencial para possibilitar uma nutrição adequada e controlar a pneumonia por aspiração, sendo um prognóstico ruim sem a sua realização. 